\title{
Axonal refractory period of single short toe extensor motor units in neuropathies and neuromuscular diseases
}

\author{
JÖRGEN BORG \\ From the Neurological Clinic, Karolinska Hospital, Stockholm, Sweden
}

SUMMARY Electromyographic recordings were carried out on 36 patients with neuropathies and neuromuscular disorders with a selectivity permitting identification of single motor unit potentials during maximal voluntary effort and after supramaximal nerve stimulation. The axonal conduction velocity and refractory period of 117 motor units were determined and the findings were compared to those in previously studied normal subjects. The axonal conduction velocity spectrum was $15-52 \mathrm{~m} / \mathrm{s}$. Fifteen per cent of all motor units had axonal conduction velocities below $30 \mathrm{~m} / \mathrm{s}$ which is below the normal range. When test stimulus strength was $10 \%$ above the axonal threshold at rest the refractory period was $1.88 \pm 0.43 \mathrm{~ms}$ which is slightly longer than the corresponding value in healthy subjects $(1.67 \pm 0.25 \mathrm{~ms})$. The relationship between the axonal conduction velocity and refractory period observed in healthy subjects did not hold for these patients. Thirty-eight per cent of all motor units with axonal conduction velocities within the normal range had refractory periods longer than $2.0 \mathrm{~ms}$ which was only infrequently observed in healthy subjects. When test stimulus strength was $50 \%$ above the axonal threshold at rest the refractory period was $1 \cdot 16 \pm 0.42 \mathrm{~ms}$ which was significantly longer $(\mathrm{p}<0.02)$ than in healthy subjects $(0.64 \pm 0.21 \mathrm{~ms})$. At this stimulus strength $40 \%$ of all motor units with axonal conduction velocities within the normal range had refractory periods above $1.0 \mathrm{~ms}$ which was never the case in healthy subjects. The significance of these findings with regard to the clinical application of the Hopf technique for determining the conduction velocity spectrum of peripheral motor nerves is discussed.

Determination of the conduction velocity in peripheral nerves is used routinely in clinical neurophysiological practice. Although still not routine, several studies of the refractory period of human peripheral nerve trunks have been reported. ${ }^{1-9}$ In both animal and man the refractory period, when measured by registration of the compound nerve action potential, may be prolonged in neuropathy. ${ }^{7810}$ In some states it may be more sensitive than the nerve conduction velocity. ${ }^{78}$ In a previous study of normal subjects reported in this journal, the refractory period of single alpha axons of short toe extensor motor units was determined. ${ }^{11}$ The refractory period was found to decrease from $1.7 \mathrm{~ms}$ to $0.6 \mathrm{~ms}$ when test stimulus strength increased from

Address for reprint requests: Dr Jörgen Borg, Neurological Clinic, Karolinska Hospital, S-104 01 Stockholm, Sweden.

Received 3 July 1981

Accepted 28 August 1981
$10 \%$ to $50 \%$ above the axonal threshold at rest. Further. there was an inverse relationship between the axonal conduction velocity and the refractory period. Finally, the refractory period was highly temperature dependent.

The primary aim of the present study was to determine whether the axonal refractory period of single alpha motor axons may be affected by a pathological process when the axonal conduction velocity remains normal. Therefore the study covered patients selected to include as many different kinds of motor unit disease as possible. Further, knowledge of the refractory period is essential to the reliability of the blocking technique, first described by Hopf, for determining the conduction velocity of slowly conducting alpha motor axons commonly used in clinical routine work. ${ }^{12}$ Hopf used one distal and one proximal supramaximal nerve stimulation and determined to what extent the proximal stimulus had to be delayed, in relation to the distal one, to 
create a maximal muscle response. From this delay the conduction velocity of the slowest conducting fibres can be calculated if correction is made for the refractory period at the site of the proximal stimulation. The second aim of this study was to determine whether the refractory period in pathological states is so similar to that in normal state that the Hopf technique can be used with the same correction factor.

\section{Materials and methods}

The study included 36 patients aged 27-72 years (13 patients older than 60 years, 21 patients 30-60 years and two patients 27 and 29 years). The diagnosis was idiopathic neuropathy in six, alcoholic neuropathy in two, uraemic neuropathy in two, diabetic neuropathy in one, Guillain-Barré in two, Charcot-Marie-Tooth in one, amyotrophic lateral sclerosis in seven, motor neuron disease in three, spinal proximal muscle atrophy (Kugelberg-Welander) in two, late onset hereditary myopathy (Welander) in six and progressive muscular dystrophy in four patients. All patients had dorsal extension paresis of the toes ranging from slight impairment to paralysis.

In the short toe extensor muscle of all patients it was possible to obtain recordings permitting identification of single motor unit potentials even during maximal voluntary effort and after supramaximal nerve stimulation by means of conventional bipolar needle electrodes (DISA 9013K0802 Electronic, Skovlunde, Denmark) presumably because of increased muscle fibre density or a reduced number of motor units or both. Only motor units with potentials which could be safely identified by their characteristic shape in both voluntary contraction and after nerve stimulation were selected for further study. The potentials were amplified and displayed on a Medelec oscilloscope no 4329, and recorded on Kodak Linograph direct print paper.

The common peroneal nerve was stimulated close to the fibular head. The deep peroneal nerve was stimulated at the ankle. The stimuli were delivered through surface eleztrodes $0.6 \mathrm{~cm}$ in diameter. The cathode was placed over the nerve and the position was adjusted so that minimum stimulus strength was required for muscle response. The anode was placed $2-3 \mathrm{~cm}$ medial to the cathode. Rectangular pulse waves of $0.2 \mathrm{~ms}$ duration were used. Stimulus strength could be gradually changed between 0 and 300 volts. After identification of a motor unit during maximal sustained voluntary contraction, the effort was reduced until the motor unit no longer discharged and electrical shocks were delivered so that the test unit potential reappeared. The peroneal nerve was first stimulated separately at the ankle and at the fibular head, permitting determination of the latency difference of the test unit potential and calculation of the conduction velocity. For the test unit stimulus strength was $10 \%$ above the axonal threshold at rest. The two stimuli were then delivered coupled to each other. The stimulus at the fibular head was initially delayed $10-15 \mathrm{~ms}$ which was long enough to permit the antidromic impulse from the ankle to pass the fibular head before stimulation there. The interstimulus time was then reduced by $0.2 \mathrm{~ms}$ stages until blocking took place at the fibular head due to refractoriness. The shortest interstimulus time without blocking could then be determined. By comparing this time with the latency difference at separate proximal and distal stimulation, the refractory period of the test motor unit could be calculated. The stimulus strength of the proximal stimulation at the double stimulation was at first $10 \%$ above the axonal threshold at rest. If there was no intolerable pain the stimulus strength was then increased to $50 \%$ above threshold.

Room temperature was held at $23-25^{\circ} \mathrm{C}$. For cases where skin temperature at the fibular head was below $32^{\circ}$, heat was applied to achieve this temperature. During the examination the temperature was regulated continuously by a Disaheater (DISA Electronic, Skovlunde, Denmark).

\section{Results}

The axonal conduction velocity and the refractory period, with test stimulus strength $10 \%$ above the axonal threshold at rest, was determined in 117 motor units in 36 patients. In each patient 1-10 motor units were studied.

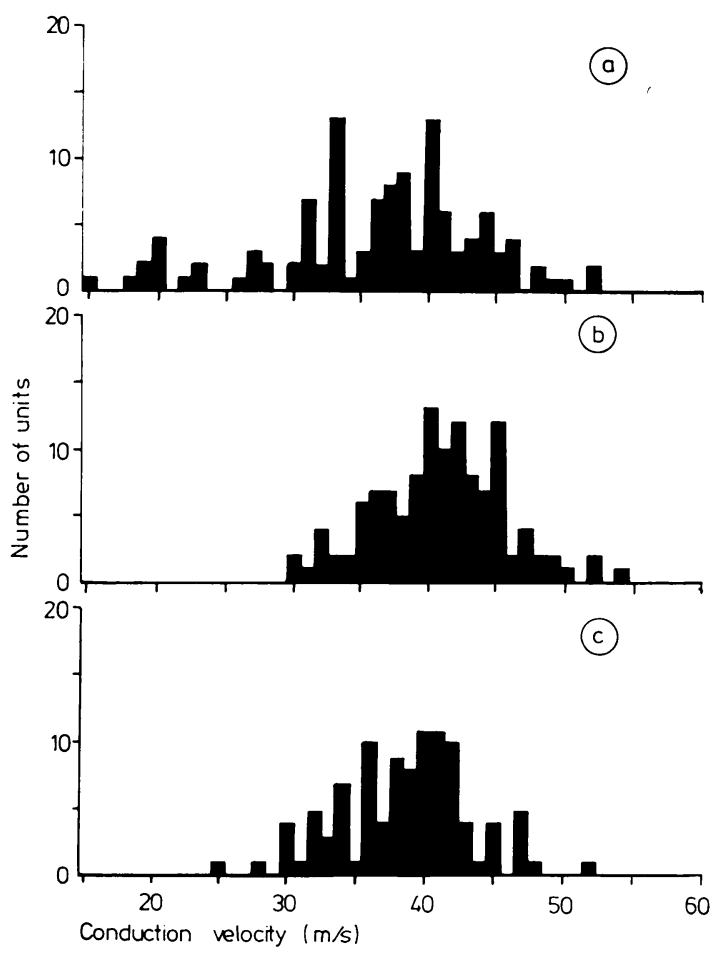

Fig 1 Axonal conduction velocity of (a) 117 motor units in patients with neuromuscular diseases and neuropathies (b) 120 motor units in young healthy subjects (c) 102 motor units in old healthy subjects. 
AXONAL CONDUCTION VELOCITY

The axonal conduction velocities ranged from $15-52 \mathrm{~m} / \mathrm{s}$. Figure 1A shows the axonal conduction velocities of the 117 motor units in the patients aged 27-72 years. Figure 1B shows the axonal conduction velocities of 120 motor units in healthy subjects aged $25-45$ years $^{13}$ and fig $1 \mathrm{C}$ the axonal conduction velocities of 102 motor units in healthy subjects aged $65-80$ years. ${ }^{14}$ The main difference between the groups is that $15 \%$ of all motor units in the patients had axonal conduction velocities below $30 \mathrm{~m} / \mathrm{s}$, while motor units with such low axonal conduction velocity were not observed in young healthy subjects and only rarely in elderly healthy subjects.

\section{AXONAL CONDUCTION VELOCITY AND REFRACTORY PERIOD AT LOW TEST STIMULUS STRENGTH}

The axonal refractory period, when test stimulus strength was $10 \%$ above the axonal threshold at rest, ranged between 0.8 and $3.1 \mathrm{~ms}$. Figure 2A shows the axonal refractory period of the 117 motor units in the patients in relation to the axonal conduction velocity. No separation of different age groups was made since normally the relation between the axonal refractory period and the conduction velocity is the same in young and old subjects. ${ }^{11}$ Figure 2B shows the axonal refractory period of

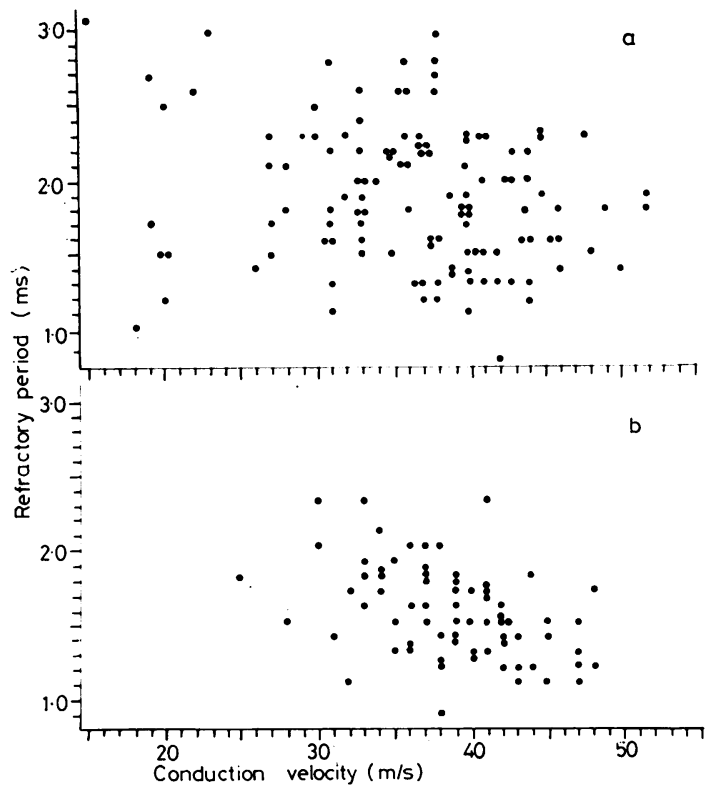

Fig 2 Axonal refractory period and conduction velocity of (a) 117 motor units in patients with neuromuscular diseases and neuropathies (b) 71 motor units in healthy subjects.
71 motor units in normal subjects in relation to the conduction velocity. In the patients, $38 \%$ of all motor units with axonal conduction velocities within the normal range, that is above $30 \mathrm{~m} / \mathrm{s}$, had refractory periods longer than $2.0 \mathrm{~ms}$. In healthy subjects such long refractory periods were observed in only $6 \%$ of the motor units. On the other hand, among patient motor units with axonal conduction velocities below the normal range, that is below $30 \mathrm{~m} / \mathrm{s}, 50 \%$ had axonal refractory periods shorter than $2.0 \mathrm{~ms}$, that is within the normal range. Thus, the axonal refractory period and conduction velocity can be affected by pathological processes independently of one another (cf discussion).

Figure $3 \mathrm{~A}$ shows the mean values of the axonal conduction velocities and the refractory periods for each of the patients. Figure 3B shows corresponding data for 12 healthy subjects. The mean value of the refractory periods in the patients was $1.88 \pm 0.43 \mathrm{~ms}$. After taking into consideration the inverse relationship between the axonal conduction velocity and refractory period and that the mean value of the conduction velocities is higher in healthy subjects, the corresponding mean value of the refractory periods in healthy subjects was $1.67 \pm 0.25 \mathrm{~ms}$. Thus, the refractory periods were slightly longer in in the patients. However, this difference was not statistically significant.

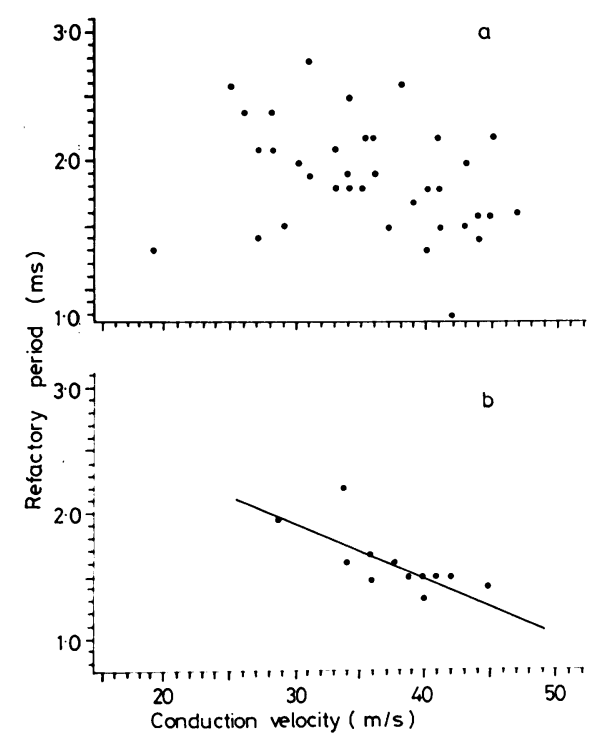

Fig 3 Mean values of the axonal refractory period and conduction velocity of each of (a) 36 patients with neuromuscular diseases and neuropathies (b) 12 healthy subjects (regression line marked as illustration). 
There was no statistically significant correlation between the axonal conduction velocity and the refractory period in the patients, in contrast to the significant correlation between these parameters in healthy subjects $(\mathrm{p}<0.01)$.

\section{AXONAL REFRACTORY PERIOD AT HIGH STIMULUS STRENGTH}

In 74 motor units from 27 patients the axonal refractory period was also determined with test stimulus strength $50 \%$ above the axonal threshold at rest. One to six motor units in each patient were studied. The axonal refractory periods at high stimulus strength ranged from 0.4 to $2.2 \mathrm{~ms}$. In $51 \%$ of the motor units it was longer than $1.0 \mathrm{~ms}$, which was never the case for healthy subjects. Forty per cent of the motor units had axonal refractory periods longer than $1.0 \mathrm{~ms}$ but axonal conduction velocities within the normal range. When the individual mean values of the axonal refractory periods were calculated for each one of the 27 patients, the refractory period exhibited a mean of $1 \cdot 16 \pm 0.42 \mathrm{~ms}$. This was significantly longer than the corresponding value in healthy subjects which was $0.64 \pm 0.21 \mathrm{~ms}$ $(\mathrm{p}<0.02)$.

\section{Discussion}

This study was screening of the axonal refractory period in single motor nerve fibres in patients where different diseases affected the motor units. No detailed examination of any particular disease was intended. The actual method of measuring the axonal refractory period provides data relevant to the clinical use of the blocking technique. However, it should be borne in mind that the refractory period is measured after an antidromic impulse and that the result depend on the state of the axon in that segment where blocking takes place. No information is available about the refractoriness of the rest of the axon.

The normal relationship between the axonal conduction velocity and the refractory period did not hold for the patients. There were motor units with axonal conduction velocities within the normal range having refractory periods longer than those normally observed. This might be due to a selective disturbance of nerve fibre properties related to the refractory period without affecting those related to the conduction velocity. However, it might also be due to a localised lesion of the nerve fibre at the test point in such a way that the conduction velocity of the rest of the nerve fibre is not significantly affected. A similar explanation could be put forward for those motor units having abnormally low axonal conduction velocities but normal refractory periods. Regardless of which mechanism underlies the finding that the axonal refractory period and the conduction velocity might be independently abnormal, the findings are significant for the reliability of the Hopf technique commonly used in clinical practice. When a refractory period correction, which would be adequate for normal subjects, is used in a case with abnormally long axonal refractory period, the calculated conduction velocity of the slowly conducting nerve fibres will be falsely low. Thus, what may be measured is the abnormality of the refractory period rather than the abnormality of the conduction velocity.

When the Hopf technique is used in normal subjects, most of the uncertainty in correction for the refractory period is avoided by sufficiently increasing test stimulus strength to be close to the absolute refractory period. This is not the case in pathological states where the refractory period at high stimulus strength might be significantly prolonged. If the refractory period is $1 \mathrm{~ms}$ longer than normal, an error of more than $10 \%$ is possible when calculating the conduction velocity of the slow fibres of the peroneal nerve and even more if shorter nerve segments are studied. However, the results obtained by the Hopf technique in clinical practice could be used as an indicator of peripheral motor nerve pathology even though abnormality sometimes is due to abnormal refractory period rather than to abnormal conduction velocity.

In conclusion, (1) abnormality of alpha axons can be detected by studies of their refractory period also when their conduction velocity is normal and (2) abnormality detected with the Hopf technique may be due either to slowing of conduction velocity or to prolonged refractory period.

\section{References}

${ }^{1}$ Betts RP, Johnston DM, Brown BH. Nerve fibre velocity and refractory period disturbances in nerve trunks. J Neurol Neurosurg Psychiatry 1976;39: 694-700.

${ }^{2}$ Gilliatt RW, Willison RG. The refractory and supernormal periods of the human median nerve. $J$ Neurol Neurosurg. Dsychiatry 1963;26:136-47.

${ }^{3}$ Kimura JA. Method for estimating the refractory period of motor fibres in human peripheral nerve. J Neurol Sci 1976;28:485-90.

${ }^{4}$ Kimura JA, Yamada T, Rodnitzky L. Refractory period of human motor nerve fibres. $J$ Neurol Neurosurg Psychiatry 1978;41:784-90.

${ }^{5}$ Kopec J, Delbeke J, McComas AJ. Refractory period studies in a human neuromuscular preparation. J Neurol Neurosurg Psychiatry 1978;41:54-64.

${ }^{6}$ Lowitzsch K, Hopf HC. Refraktärperiode und Übermittlung frequenter reizserien in gemischten 
peripheren Nerven des Menschen. $J$ Neurol Sci 1972:17:255-70.

${ }^{7}$ Lowitzsch K, Hopf HC. Refraktärperioden und frequente Impulsfortleitung im gemischten $n$. ulnaris des Menschen bei Polyneuropathien. Z Neurol $1973 ; 205: 123-44$.

${ }^{8}$ Lowitzsch K, Göhring U, Hecking E, Köhler H. Refractory period, sensory conduction velocity and visual evoked potentials before and after haemodialysis. J Neurol Neurosurg Psychiatry 1981;44: 121-8.

${ }^{9}$ Tackman W, Lehmann HJ. Refractory period in human sensory nerve fibres. Eur Neurol 1974;12: 277-92.

${ }^{10}$ Low PA, McLeod JG. Refractory period, conduction of trains of impulses, and effect of temperature on conduction in chronic hypertrophic neuropathy. Electrophysiological studies on the Trembler mouse. J Neurol Neurosurg Psychiatry 1977;40:434-47.

11 Borg J. Axonal refractory period of single short toe extensor motor units in man. $J$ Neurol Neurosurg Psychiatry 1980;43:917-24.

${ }^{12}$ Hopf HC. Untersuchungen über die Unterschiede in der Leitgeschwindigkeit motorischer Nervenfasern beim Menschen. Dtsch $Z$ Nervenheilk 1962;183: 579-88.

${ }^{13}$ Borg J, Grimby L, Hannerz J. Axonal conduction velocity and voluntary discharge properties of individual short toe extensor motor units in man. $J$ Physiol (Lond) 1978;277:143-52.

14 Borg J. Properties of single extensor digitorum brevis motor units in elderly man. Muscle Nerve (in press). 